\title{
PERENCANAAN HOTEL RESORT PULAU JEMUR DENGAN PENDEKATAN ARSITEKTUR TRADISIONAL
}

\author{
Rizki Kurnia Arum, Hendri Silva,Imbardi \\ Program Studi Arsitektur, Fakultas Teknik, Universitas Lancang Kuning \\ Jl. Yos Sudarso km. 8 Rumbai, Pekanbaru, Telp. (0761) 52324 \\ Email: rizkiarum.14@gmail.com, Hsilva@unilak.ac.id,Imbardi@unilak.ac.id
}

\begin{abstract}
ABSTRAK
Pulau Jemur berada di Kabupaten Rokan Hilir, pulau ini terletak disebelah timur laut dan berjarak sekitar $700 \mathrm{~m}$ dari pulau labuhan bilik, Pulau ini merupakan gugusan Kepulauan Aruah. Pulau Jemur memiliki potensi alam yaitu pasir putih, penangkaran penyu, sunrise, batuan terjal dan lain sebagainya. Selain untuk berwisata pulau ini dapat dijadikan sebagai pusat edukasi penangkaran penyu.

Terkait dengan hal tersebut dibutuhkan perencanaan akomodasi seperti perencanaan Hotel Resort dengan pendekatan Arsitektur Tradisional. Adapun tujuan perencanaan yaitu untuk menemukan planning dan programming serta konsep perancangan Hotel Resort Pulau Jemur.

Metode penelitian yang di gunakan yaitu metode analisis terhadap pelaku/manusia, metode analisis lingkungan, dan metode analisis bangunan. Adapun hasilnya berupa konsep dengan penerapan Arsitektur Tradisional suatu bangunan dan menghasilkan hasil sebuah rancangan.
\end{abstract}

Kata Kunci: Konsep, Hotel Resort, Pulau Jemur.

\section{ABSTRACT}

Pulau Jemur is located in Rokan Hilir Regency, the island is located in the northeast and is about 700m from the island, the port is a port, this island is a group of Aruah Islands. Jemur Island has natural potential namely white sand, turtle breeding, sunrise, steep rocks and so on. In addition to traveling the island can be used as an education center for turtle breeding.

Related to this, it is necessary to plan accommodation such as planning a Resort Hotel with a Traditional Architecture approach. The purpose of planning is to find planning and programming and the concept of Pulau Jemur Resort Hotel design.

The research method used is the method of analysis of the perpetrator / human, the method of environmental analysis, and the method of building analysis. The result is a concept with the application of the traditional architecture of a building and produce the results of a design.

Keywords: Concept, Hotel Resort, Pulau Jemur. 


\section{PENDAHULUAN}

Menurut Badan Perencanaan Pembangunan Daerah Kabupaten Rokan Hilir bahwa "Potensi Pulau Jemur dapat berkembang menjadi pusat Resort, adapun berbagai aktivitas wisata yang dapat dilakukan adalah berselancar, berenang, mendayung dan sebagainya. Dengan mengoptimalkan sumber daya pemerintah daerah pengembangan destinasi akan meningkat, kegiatan pengembangkan , serta investor asing, peningkatan peran fungsi masyarakat dan swasta dalam pengembangan kepariwisataan serta atraksi wisata.(sumber : Badan Perencanaan Pembangunan Daerah Kabupaten Rokan Hilir)

Pulau Jemur berada di sebelah timur laut dan berjarak sekitar $700 \mathrm{~m}$ dari Pulau Labuan Bilik. Struktur pulau ini terdiri dari hamparan pasir di sisi selatan dan utara. Luas pulau ini adalah sekitar 17,8 ha. Hamparan pasir yang ada di bagian utara dan selatan pulau sangat berdekatan dengan pulau kecil di depannya (jarak $50 \mathrm{~m}$ ) yang juga memiliki hamparan pasir merupakan tempat penyu bertelur . ( Sumber: Masterplan Infrastruktur di Gugusan Kepulauan Aruah)

\section{METODE PENELITIAN}

Metode yang di gunakan adalah pengumpulan datadata yang terkait dengan perencanaan dan perancangan Hotel Resort .

\subsection{Studi Pustaka}

Mengumpulkan data dari perpustakaan berupa buku, jurnal dan karya ilmiah lainnya yang berhubungan dengan perencanaan Hotel Resort, Arsitektur Tradisional, Aktivitas wisata dan lain sebagainya.

\subsection{Studi Banding}

Melakukan peninjauan langsung ke Kecamatan Anyer, Kbaupaten Serang Provinsi Banten. Tepatnya di Hotel Resort Acacia.

\subsection{Wawancara}

Melakukan wawancara kepada pihak pemerintahan di dinas Badan Perencanaan Pembangunan Daerah Kabupaten Rokan Hilir.

\section{HASIL DAN PEMBAHASAN}

Kabupaten Rokan Hilir terletak di Provinsi Riau, kabupaten yang masih berbenah dibidang pembangunan khususnya kepariwisataan ini terus mempersiapkan sarana dan prasarana pendukung untuk meningkatkan kunjungan wisatawan yang ingin berlibur di Kabupaten Rokan Hilir. Wisatawan juga dapat mengunjungi salah satu wisata bahari di Pulau Jemur.

Pulau Jemur merupakan satuan kepulauan Aruah yang dikelilingi oleh laut dengan struktur pantai berbatu dan bertebing terjal, hanya sebagian kecil berpasir dan mempunyai perbedaan air laut pasang maupun surut. (Sumber: laporan pendahuluan infrastruktur pulau arwah)
Pengambilan site pada lokasi Pulau Jemur merupakan sasaran utama dari potensi yang mendukung di Kabupaten Rokan Hilir.

Nama Resmi : Pulau Jemur Kepulauan Arwah

Kecamatan : Pasir Limau Kapas

Kabupaten : Rokan Hilir

Provinsi : Riau

Batas Wilayah

Utara : Menghadap Teluk Indah ,Malaysia

Timur : Menghadap Silangor, Malaysia

Selatan : Menghadap Bagansiapiapi

Barat :Menghadap Tanjung Balai Asahan,

Sumatera utara

Luas Wilayah : $17,8 \mathrm{Ha}$

Luas Site darat $\quad: 2.8 \mathrm{Ha}$

\subsection{Analisis Tapak}

Lahan yang digunakan dalam perencanaan seluas $2,8 \mathrm{Ha}$ yang merupakan hamparan tanah kosong dan bebatuan yang mengarah ke Timur Hal ini merupakan potensi yang menarik untuk membangun Hotel Resort dengan menggambil view matahari terbit dan mengarah pada pulau diseberangnya.

\section{Dimensi Tapak}

Pengambilan dimensi tapak di perkirakan Berdasarkan kebutuhan ruang dalam perencanaan, luas site adalah.

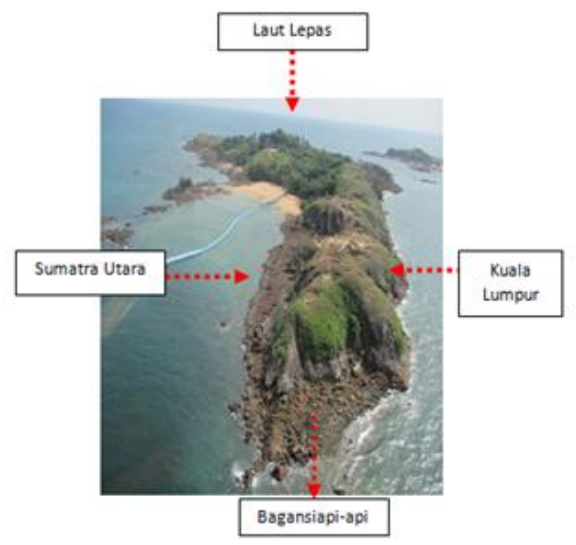

Gambar 1. Akses Menuju Lokasi (Sumber: google.com)

\subsection{Analisis view}

Orientasi view mengarah pada bagian timur, analisis ini mengambil rotasi matahari terbit untuk meningkatkan potensi pada bangunan,dan juga memiliki nilai jual yang tinggi. Selain itu potensi sekitar tapak juga sangat menarik, karena memiliki potensi wisata edukasi dan zona lainya 

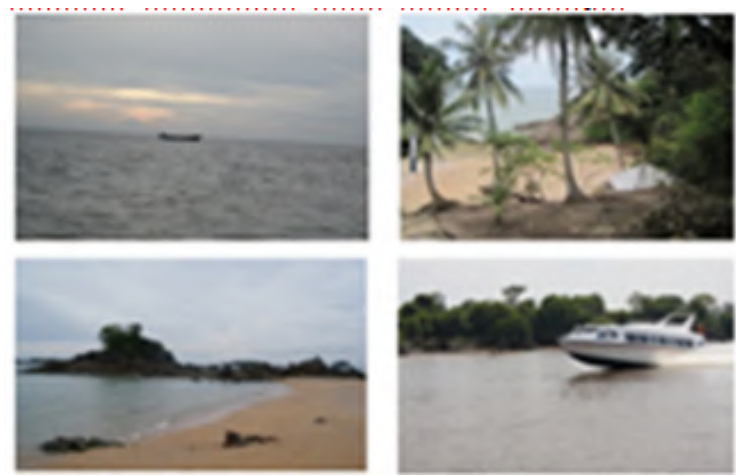

Gambar 2. view sekitar tapak

(Sumber: google.com)

\subsection{Analisis Topografi}

Dilihat dari kondisi tanah dan campuran batuan yang sangat bagus untuk penempatan bangunan dengan penekan kondisi alam yang masih alami. Selain itu kontur menjadi daya dukung bagi bangunan tanpa melakukan cut and fil.

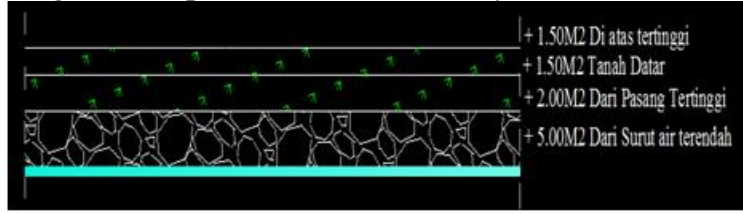

Gambar 3. Sketsa Topografi

(Sumber: Dokumentasi Pribadi)

\subsection{Analisis Sirkulasi}

Kondisi eksisting tapak terdapat 1 akses jalan yang merupakan penghubung ke penangkaran penyu dan perumahan navigasi. Pencapaian di tempuh dengan berjalan kaki. Adapun sirkulasi yang akan di rencanakan yaitu penambahan jetty dan sirkulasi pendukung lainnya.

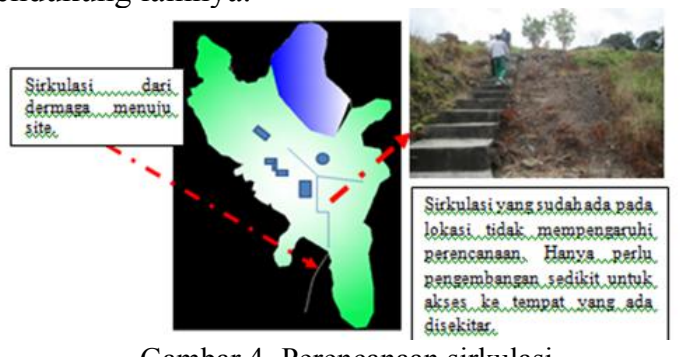

Gambar 4. Perencanaan sirkulasi

(Sumber: Dokumentasi Pribadi)

\subsection{Analisis Vegetasi}

Vegetasi ditentukan sebagai pendukung pada penghawaan agar lebih alami, selain angin laut yang mendukung juga pohon menjadi peran utama dalam lingkungan. Baik secara estetis, pelindung dan pendukung sirkulasi. Jenis - jenis taman yang dapat mendukung fungsi tersebut antara lain :
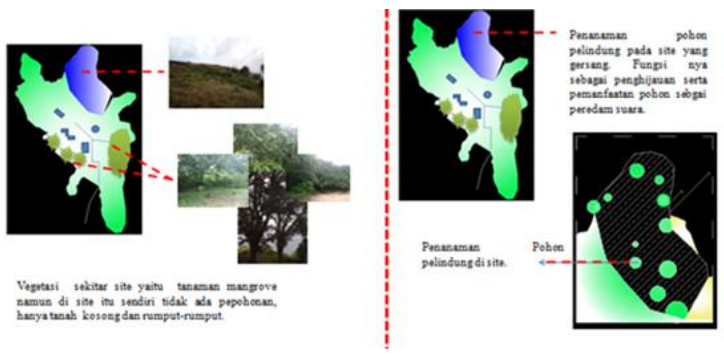

Gambar 5. Analisis vegetasi

(Sumber: Dokumentasi Pribadi)

\subsection{Analisis Aktifitas dan Kebutuhan Ruang}

3.2.1 Tabel Pengelola

\begin{tabular}{|c|c|c|c|}
\hline No & Pelake & Kegiatan & Kebutuban Rasng \\
\hline \multirow{6}{*}{1} & \multirow{6}{*}{$\begin{array}{l}\text { General } \\
\text { Menager }\end{array}$} & $\begin{array}{l}\text { Menerima } \quad \text { Tamu } \\
\text { Khusus }\end{array}$ & R. Tamu \\
\hline & & Memeriksa laporan & $\begin{array}{l}\text { R. Kerja General } \\
\text { Manager }\end{array}$ \\
\hline & & Rapat & R. Rapat \\
\hline & & Mengawasi Pekerjaan & R. Staff \\
\hline & & Buang air & Toilet \\
\hline & & Isoma & R. Sholat \\
\hline \multirow{5}{*}{2} & \multirow{5}{*}{$\begin{array}{l}\text { Acconting } \\
\text { Manager }\end{array}$} & $\begin{array}{l}\text { Membuat Laporan } \\
\text { Pembukuan }\end{array}$ & R. Acconting Manger \\
\hline & & $\begin{array}{l}\text { Mengatur Pemasukan } \\
\text { dan Pengeluaran }\end{array}$ & R. Acconting Manger \\
\hline & & Rapat & R. Rapat \\
\hline & & Buang air & Toilet \\
\hline & & Isoma & R. Sholat \\
\hline \multirow{2}{*}{3} & \multirow{2}{*}{ Front Office } & Melayani Tamu & R. Front desk \\
\hline & & Melayani pendaftaran & R. Registrasi \\
\hline
\end{tabular}

\begin{tabular}{|c|c|c|c|}
\hline & & $\begin{array}{l}\text { Melayani pembayaran } \\
\text { Penginapan }\end{array}$ & Kasir \\
\hline & & Memberikan informasi & Resepsionis \\
\hline & & $\begin{array}{l}\text { Menerima Penitipan } \\
\text { Barang }\end{array}$ & R. Loker \\
\hline & & Rapat & R. Rapat \\
\hline & & Buang air & Toilet \\
\hline & & Isoma & R. Sholat \\
\hline \multirow{4}{*}{4} & \multirow{4}{*}{$\begin{array}{l}\text { Marketing } \\
\text { Manager }\end{array}$} & $\begin{array}{l}\text { Memasarkan } \\
\text { Akomodasi yang ada di } \\
\text { Pulau Jemur }\end{array}$ & R. sales manager \\
\hline & & Rapat & R. Rapat \\
\hline & & Buang air & Toilet \\
\hline & & Isoma & R. Sholat \\
\hline
\end{tabular}




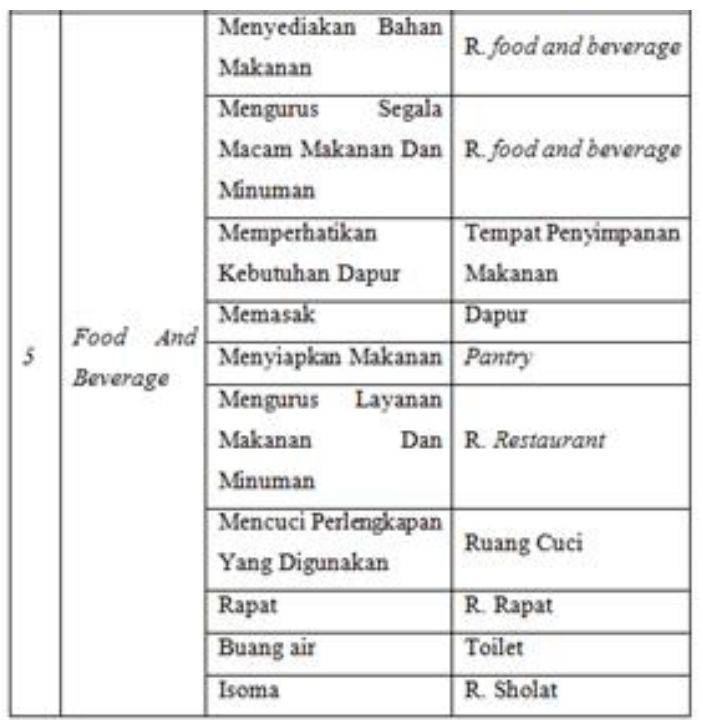

\begin{tabular}{|c|c|c|c|}
\hline \multirow{7}{*}{6} & \multirow{7}{*}{$\begin{array}{l}\text { Exclustive } \\
\text { House } \\
\text { Keeping }\end{array}$} & $\begin{array}{l}\text { Mengutamakan } \\
\text { kebersihan Kamar }\end{array}$ & R. house keoping \\
\hline & & $\begin{array}{l}\text { Menyediakan } \\
\text { pencucian pakaian }\end{array}$ & R. Laundiry \\
\hline & & $\begin{array}{l}\text { Menyediakan } \\
\text { Kelengkapan Kamar }\end{array}$ & R. periengkapan \\
\hline & & $\begin{array}{l}\text { Menyimpan Peralatan } \\
\text { Kebersihan }\end{array}$ & Gudang \\
\hline & & Rapat & R. Rapat \\
\hline & & Buang air & Toilet \\
\hline & & Isoma & R. Sholat \\
\hline \multirow{3}{*}{7} & \multirow{3}{*}{$\begin{array}{l}\text { Chilef } \\
\text { Engineer }\end{array}$} & $\begin{array}{l}\text { Memperhatikan } \\
\text { Utilitas Bangunan }\end{array}$ & R. Chef Engtneer \\
\hline & & $\begin{array}{l}\text { Menjaga Fasilitas } \\
\text { Yang Tersedia }\end{array}$ & Lapangan \\
\hline & & $\begin{array}{l}\text { Melakukan } \\
\text { Pemeriksaan Dan } \\
\text { Perbaikan Yang Rusak }\end{array}$ & Lapangan \\
\hline \multirow[t]{2}{*}{8} & \multirow{2}{*}{$\begin{array}{l}\text { Assistant } \\
\text { Manager }\end{array}$} & $\begin{array}{l}\text { Berkerja sesuai dengan } \\
\text { bidangnya }\end{array}$ & R. Assistant Manager \\
\hline & & Mengawasi karyawan & R. karyawan \\
\hline 9 & $\begin{array}{l}\text { Staff/Karya } \\
\text { wan }\end{array}$ & $\begin{array}{l}\text { Berkerja sesuai dengan } \\
\text { bidangnya Masing- } \\
\text { masing }\end{array}$ & R. Staff/Karyawan \\
\hline \multirow{4}{*}{10} & \multirow{4}{*}{$\begin{array}{l}\text { Security } \\
\text { Personal } \\
\text { Manager }\end{array}$} & $\begin{array}{lr}\text { Menjaga } & \text { Kemanan } \\
\text { akses } & \text { maupun } \\
\text { Keamanan Bangunan }\end{array}$ & Pos Jaga \\
\hline & & $\begin{array}{l}\text { Mengawasi segala } \\
\text { Kegiatan dilingkup } \\
\text { Hotel Resort }\end{array}$ & Lapangan \\
\hline & & Memeriksa CCTV & R CCTV \\
\hline & & Tukar Shift Kerja & R. Secturity \\
\hline
\end{tabular}

\begin{tabular}{|c|c|c|}
\hline \multirow[b]{2}{*}{ Rekreasi } & $\begin{array}{l}\text { Mengatur Perjalanan } \\
\text { Menuju pulau-pulau } \\
\text { sekitar dengan Jetskt }\end{array}$ & R. Resepsionis \\
\hline & $\begin{array}{l}\text { Menikmati Keindahan } \\
\text { Alam sekitar dan } \\
\text { Melihat Penakaran } \\
\text { Penyu }\end{array}$ & Pantai \\
\hline \multirow{3}{*}{ Penunjang } & Menerima Tamu & Lobby \\
\hline & Makan Dan Minum & R. Restaurant dan bar \\
\hline & $\begin{array}{l}\text { Menukar Uang dan } \\
\text { Mengambil Uang }\end{array}$ & $\begin{array}{l}\text { Money Changer, dan Mesin } \\
\text { ATM }\end{array}$ \\
\hline
\end{tabular}

\begin{tabular}{|c|c|c|}
\hline $\begin{array}{l}\text { Jenks } \\
\text { Kegiatas }\end{array}$ & Aktintas & Kebutahan Ruans \\
\hline \multirow{5}{*}{ Pendahuluan } & Datang & Dermaga \\
\hline & Meminta Informasi & R. Information Desk \\
\hline & Menunggu & Lobby \\
\hline & Chek in & R. Front Desk \\
\hline & Menuju Kamar & Sarana Sirkulasí \\
\hline \multirow{6}{*}{ Utama } & Istirahat & R. Kamar \\
\hline & $\begin{array}{l}\text { Menghadiri Seminar, } \\
\text { Merting }\end{array}$ & R. Function Hall \\
\hline & Jalan-jalan Area Rosort & Open Space Pre Function \\
\hline & Makan & R. Restaurant \\
\hline & Mandi & Toilet \\
\hline & Sholat & R. Sholat \\
\hline \multirow{4}{*}{ Olahraga } & Jogging & Jogging Track \\
\hline & Berenang & Kolam Renang \\
\hline & Bermain Voli & Lapangan Voli \\
\hline & Finess/ Gym & Fimess Center \\
\hline
\end{tabular}

\begin{tabular}{|l|l|l|}
\hline \multirow{7}{*}{ Penutup } & Relaksasi & R. Spa \\
\cline { 2 - 3 } & Berbelanja & Rumah Pondok \\
\cline { 2 - 3 } & Penitipan Barang & R. Safe Deposit Box \\
\cline { 2 - 3 } & $\begin{array}{l}\text { Memangal Jasa } \\
\text { Transportasi }\end{array}$ & R.Call Station Transport \\
\cline { 2 - 3 } & $\begin{array}{l}\text { Cek out } \\
\text { transportasi }\end{array}$ & R. Reseptionis \\
\cline { 2 - 3 } & Pulang & Call station Transport \\
\hline
\end{tabular}

3.2.2 Tabel Pengunjung 


\subsection{Analisis Besaran Ruang}
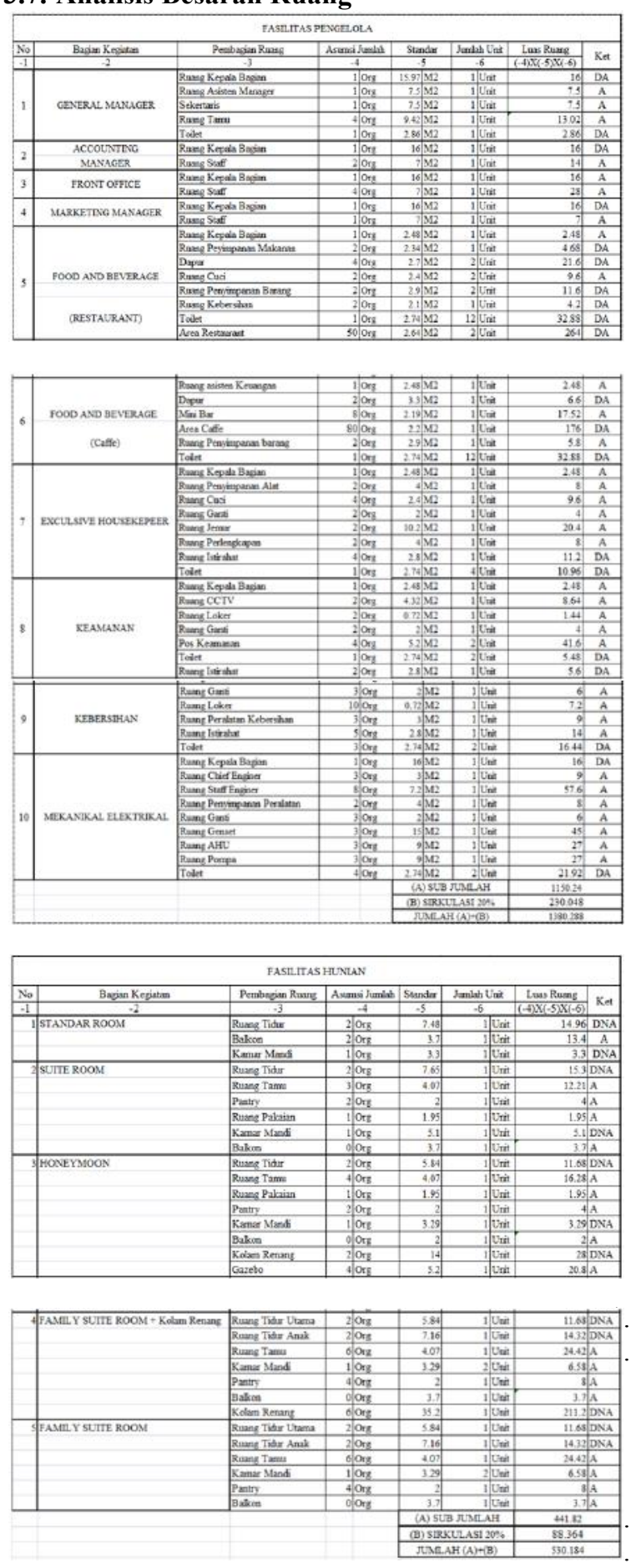
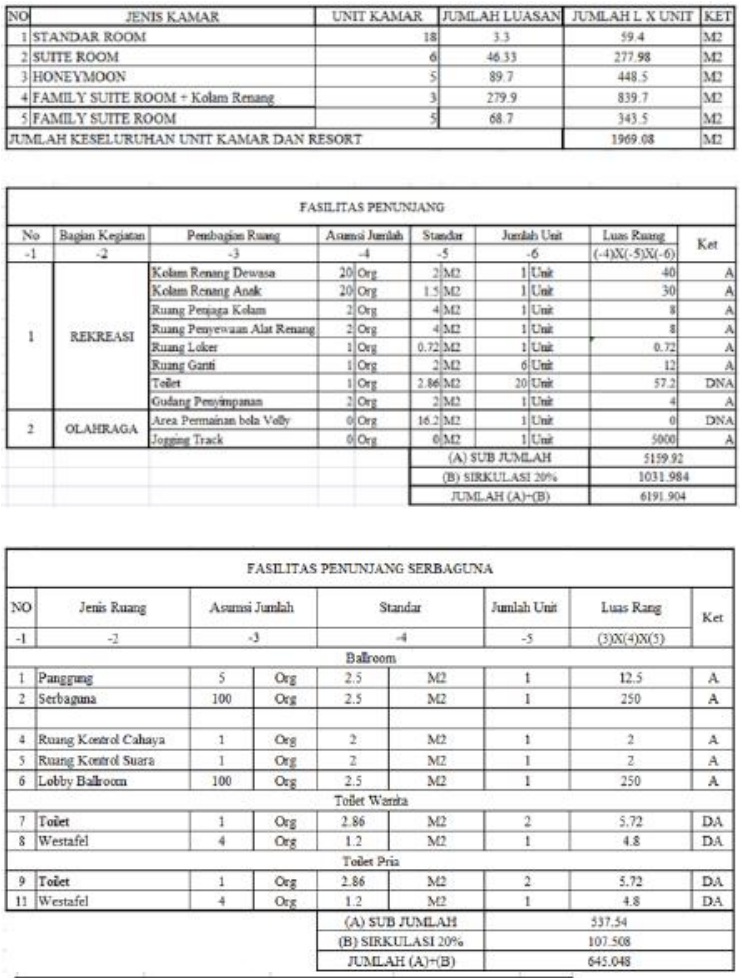

TOTAL LUASAN KESELURUHAN

\begin{tabular}{|l|r|r|}
\hline Fasilitas Pengelola & 1380.288 & $\mathrm{M} 2$ \\
\hline Fasilitas Penyewa (Unit Hunian) & 1969.08 & $\mathrm{M} 2$ \\
\hline Fasilitas Penunjang & 6191.904 & $\mathrm{M} 2$ \\
\hline Function Room & 537.54 & $\mathrm{M} 2$ \\
\hline Luas Kesehuruhan & 10078.81 & $\mathrm{M} 2$ \\
\hline
\end{tabular}

\subsection{Analisis fasilitas Hotel Resort}

Perencanaan Hotel resort yang akan dibangun adalah hotel resort dengan kriteria kamar berdasarkan unit yaitu 80 Unit:

Tipe Hotel

$\begin{array}{ll}\text { Standard room } & : 18 \text { Unit } \\ \text { Suite room } & : 6 \text { Unit }\end{array}$

(1 Unit Kamar 2 Tempat tidur)

Tipe Resort

Honeymoon Suite Resort :5 unit Resort

Family Suite Resort $\quad: 8$ unit Resort

3.

Penunjang

1. Restaurant :2 unit

2. Caffe : 1 unit

4. Function room : 1 unit

5. Rekreasi dan olahraga : 1 unit

6. Lounge : 1 unit

7. Taman : 1 unit

3.9. Analisis Aspek Bangunan 


\subsubsection{Analisis Bentuk Dasar Bangunan}

Bentuk dasar bangunan menggunakan 1 bentuk yaitu persegi. Yang di analisa berdasarkan orientasi matahari. Arsitektur Tradisional Melayu akan diterapkan pada semua bangunan yang ada disite, dengan mengadopsi beberapa rumah Tradisional Melayu yang ada di Rokan Hilir khususnya Rantau Bais tepi sungai . Di ambil dari Prinsip-prinsip yang diterapkan dalam Arsitektur Tradisional pada umumnya yaitu :

Bawah, Tengah, Atas

Bawah = Umpak

Tengah $=$ Ruang dan Dinding

Atas = Atap atau loteng

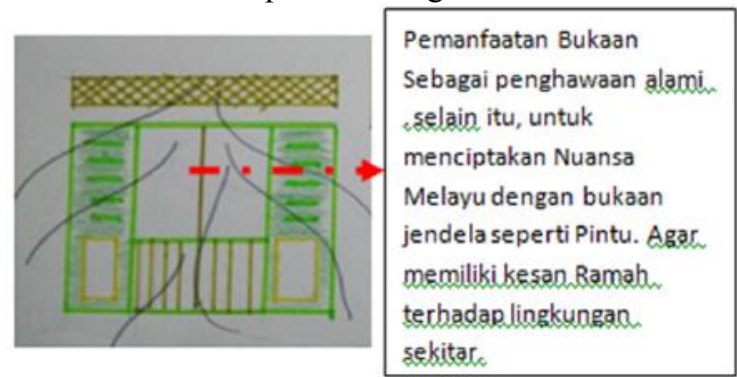

Gambar 6. Perencanaan sirkulasi

(Sumber: Bahan kuliah Sudarmin S.T.,M.T)

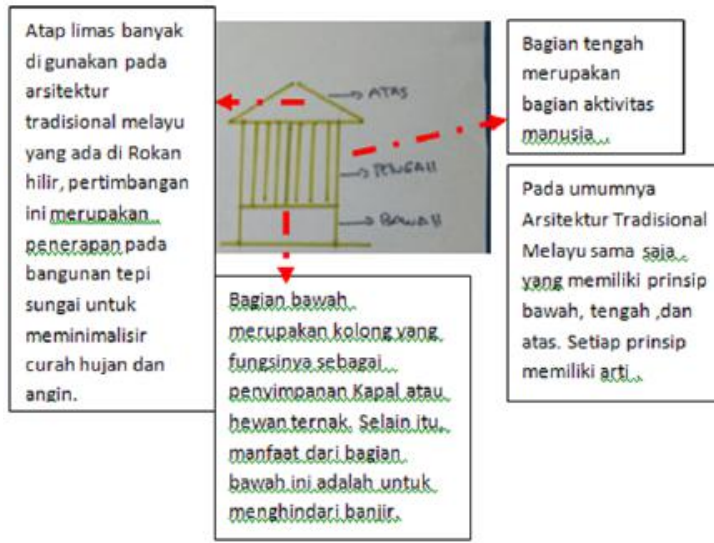

Gambar 7. Konsep Dasar Perancangan.

(Sumber: Bahan kuliah Sudarmin S.T.,M.T)

\subsection{Konsep Dasar Perancangan}

Konsep dasar perencanaan hotel resort yaitu dengan pendekatan arsitektur tradisional, yang di angkat dari arsitektur tradisonal Melayu yang berada di Rokan hilir yaitu tanpa menghapus identitas suatu bangunan yang ada di Rokan Hilir. Penerapan konsep ini bertujuan untuk meningkatkan Nilai Arsitektur tradisional Melayu agar tidak punah. Dan Konsep ini akan ditujukan pada pola ruang dan Eksterior bangunan .

\subsection{Konsep Zoning Kawasan}

Zoning merupakan pembagian zona dalam mendesain, adapun beberapa bagian dari zoning yaitu:

\section{Zona Parkir Kapal (dermaga)}

Perencanaan Zona parkir berada di pinggir pantai atau penambahan dermaga untuk mengunjung Hotel Resort, agar mempermudah akses menuju tapak. Namun, sebelum pengunjung Hotel Resort memasuki kawasan site, Kapal pengunjung baik dari lokal maupun internasional harus izin ke pos Angkatan Laut.

\section{Zona Bangunan}

Zona bangunan terbagi menjadi beberapa massa bangunan, untuk bangunan utama(Hotel) berada di pinggir site sebelah selatan untuk mempermudah akses ke tempat publik, dan untuk cottege berada diatas air untuk mendapatkan nuansa air laut yang berwarna biru.

\section{Zona Edukasi}

Tersedianya tempat penangkaran penyu yang dapat digunakan sebagai pusat edukasi sehingga pemanfaatan lahan tersebut menjadi objek daya tarik wisatawan.

\section{Zona Rekreasi}

Karena penempatan yang strategis maka zona rekreasi semakin baik bagi pengunjung karena pengunjung tidak hanya berada di pulau jemur saja namun biasa beranjak ke pulau-pulau sekitar, wisata air, wisata alam dan lainnya.

\section{Zona Pemerintah}

Zona pemerintah merupakan suatu keamanan bagi pulau tersebut, sehingga dengan adanya perencanaan Hotel Resort, zona pemerintah dapat menjadi lebih aktif lagi.

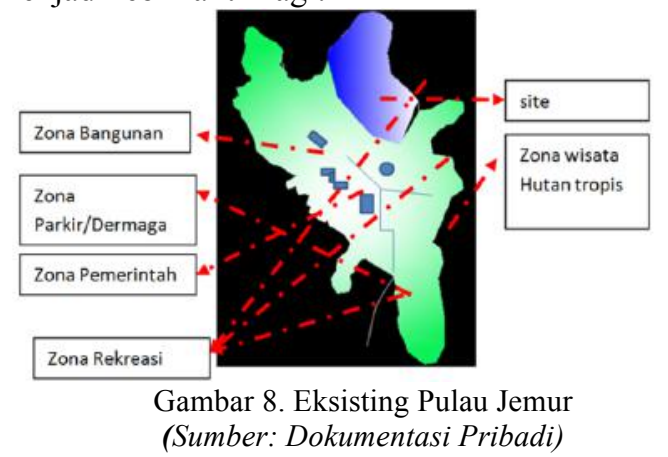




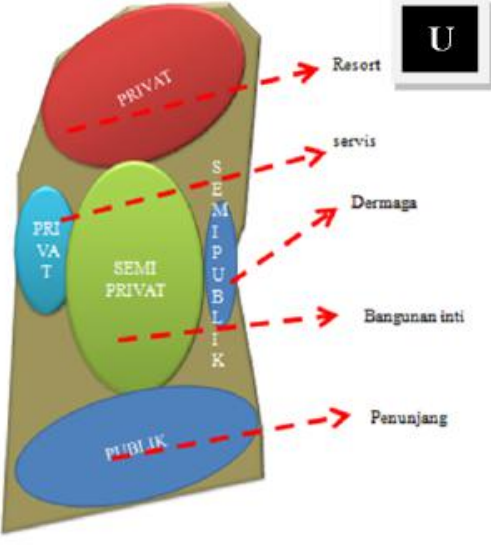

Gambar 9. Pembagian zona site (Sumber : Dokumentasi pribadi)

\subsection{Konsep Perwujudan Arsitektur Tradisional}

Perwujudan bangunan diambil dari rumah tradisionl Melayu yang ada di Rokan Hilir. Perwujudan ini diterapkan pada bangunan resort yang diambil dari elemen jendela, serta Ukiran Rumah Tradisional Melayu yang ada di Kecamatan Rantau Bais.

Dan bentuk perwujudan bangunan Penunjang akan diterapkan pada bentuk dasar bangunan melayu yaitu dari bawah, tengah, dan atas. Yang akan menggunakan umpak, jendela dan ventilasi sebagai penghawaan alami, dan juga atap limas sebagai identitas rumah melayu yang ada di Kabupaten Rokan Hilir.

\subsection{Konsep Ruang Dalam}

Bentuk ruang dalam menggunkan material alami seperti kayu, batu-batuan dan lain sebagainya yang diselaraskan dengan fungsi dalamnya.

\subsection{Konsep Ruang Luar}

Meminimalisirkan kerusakan lahan agar dapat memanfaatkan ruang yang sudah tersedia seperti pemanfaatan Kontur, orientasi matahari dan view pendukung lainnya secara alami.

\subsection{Hasil Perancangan}

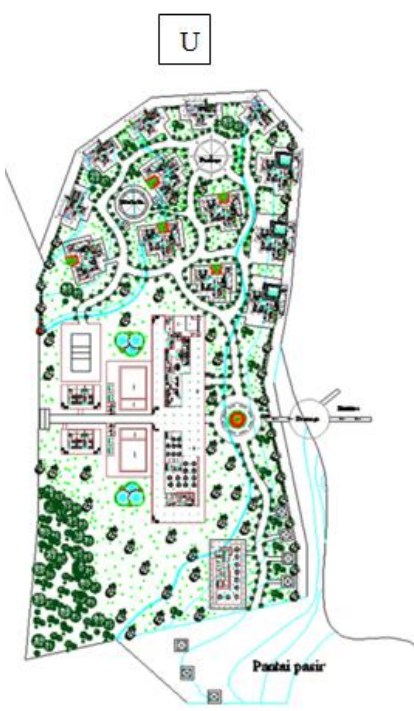

Gambar 10. Site Plan (Sumber : Dokumentasi pribadi)
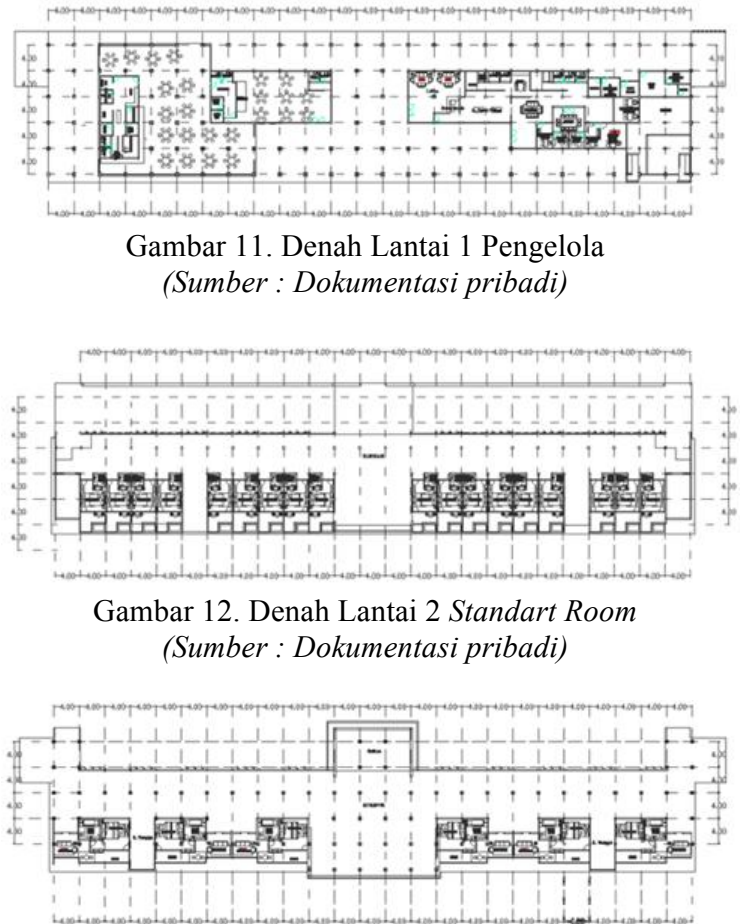

Gambar 13. Denah Lantai 3 Suit Room (Sumber : Dokumentasi pribadi)
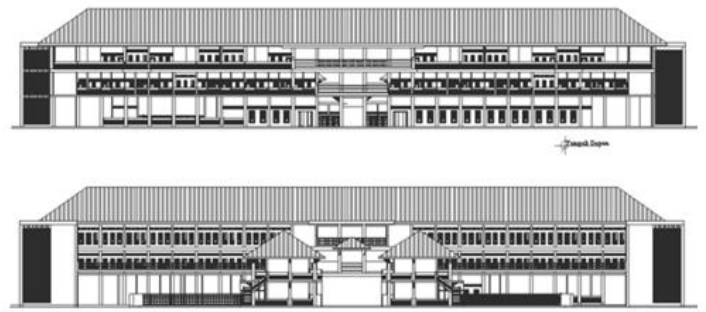

Gambar 14. Tampak Depan Dan Belakang Bangunan Utama

(Sumber : Dokumentasi pribadi) 


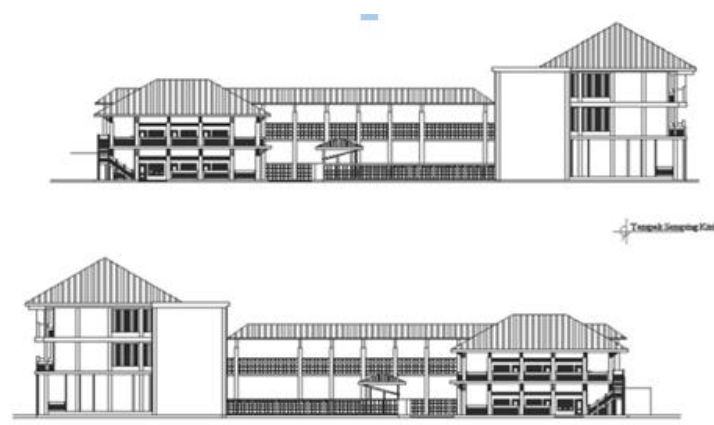

Gambar 15. Tampak Samping Kanan dan Kiri Bangunan Utama

(Sumber : Dokumentasi pribadi)
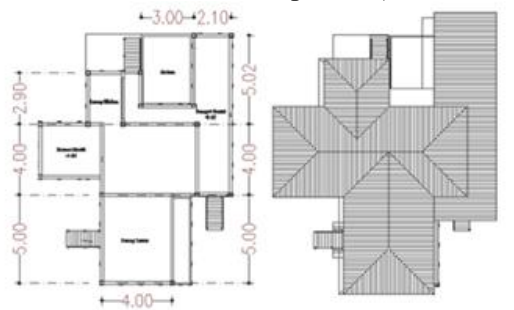

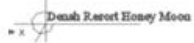

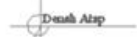

Gambar 16. Denah Resort Honeymoon

(Sumber : Dokumentasi pribadi)

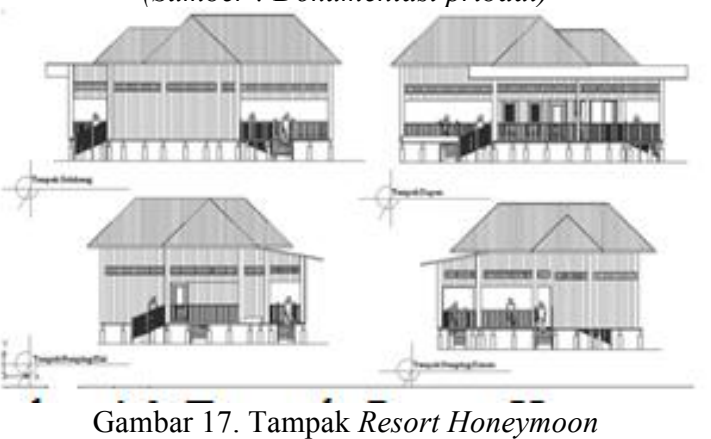

Gambar 17. Tampak Resort Honeymoon (Sumber : Dokumentasi pribadi)

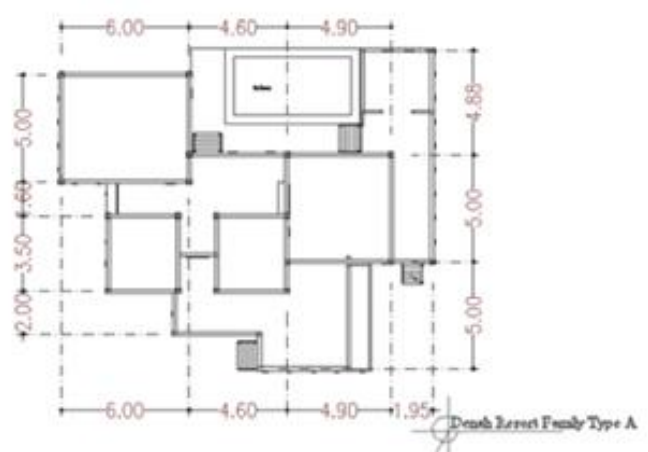

Gambar 18. Denah Resort Family Type A (Sumber : Dokumentasi pribadi)

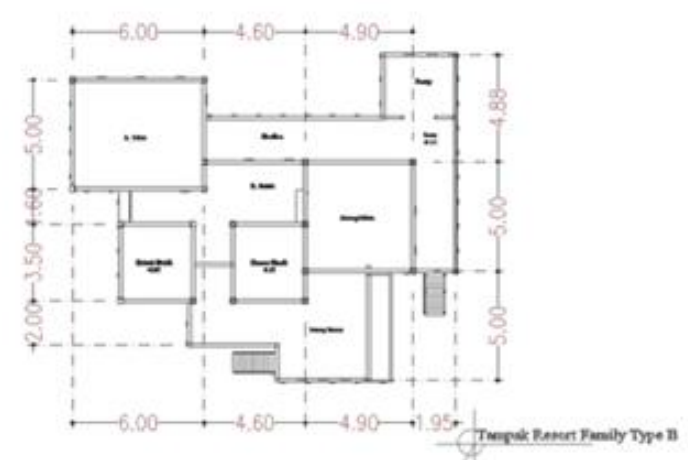

Gambar 19. Denah Resort Family Type B (Sumber : Dokumentasi pribadi)
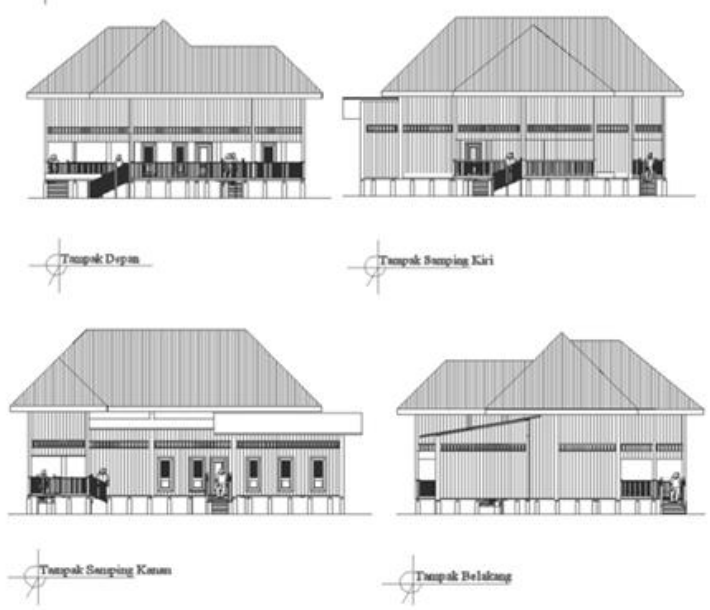

Gambar 20. Tampak Resort Family (Sumber : Dokumentasi pribadi)

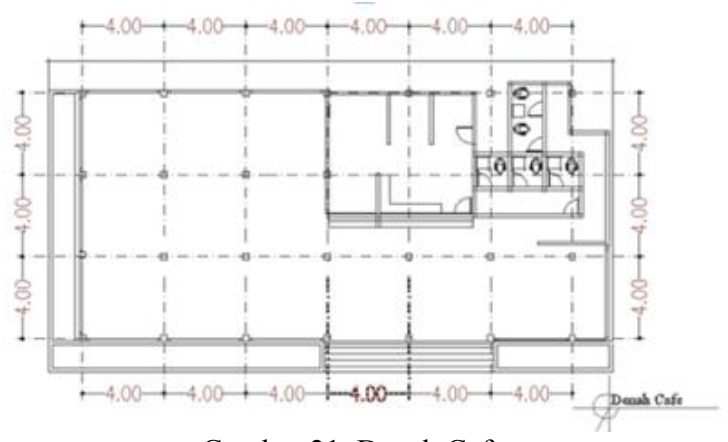

Gambar 21. Denah Cafe

(Sumber : Dokumentasi pribadi)

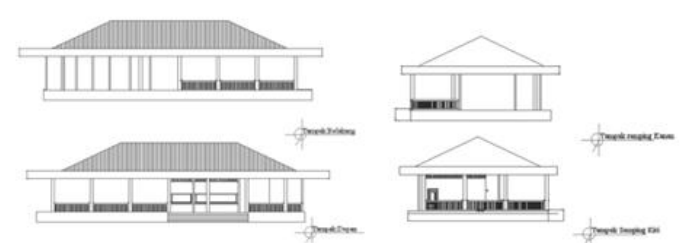

Gambar 22. Tampak Cafe (Sumber : Dokumentasi pribadi) 

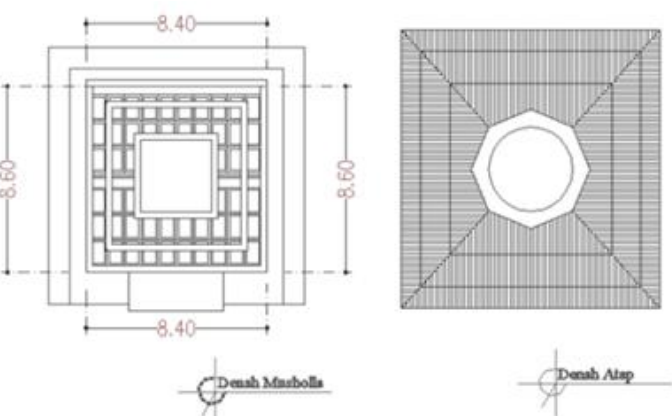

Gambar 23. Denah Musholla (Sumber : Dokumentasi pribadi)

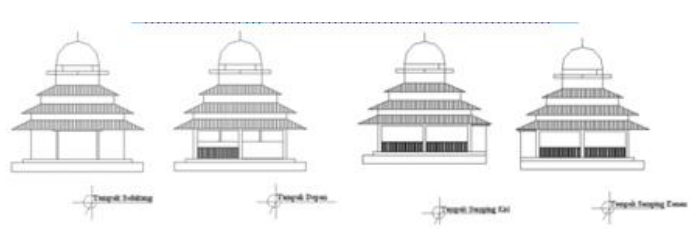

Gambar 24. Tampak Musholla

(Sumber : Dokumentasi pribadi)

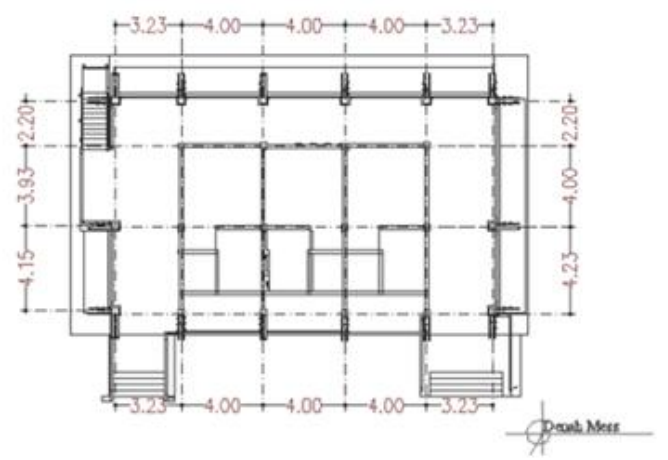

Gambar 25. Denah Mess (Sumber : Dokumentasi pribadi)
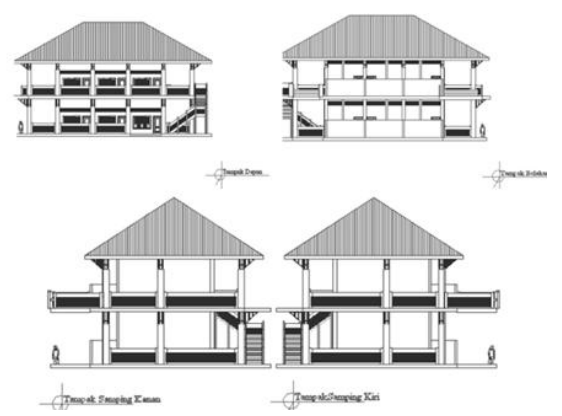

Gambar 26. Tampak Mess

(Sumber : Dokumentasi pribadi)

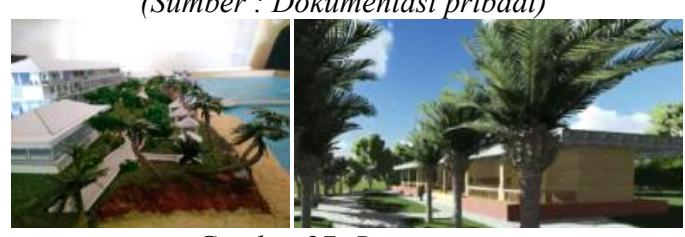

Gambar 27. Restaurant

(Sumber : Dokumentasi pribadi)

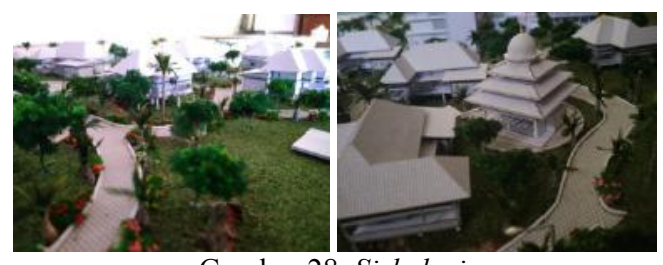

Gambar 28. Sirkulasi

(Sumber: Dokumentasi pribadi)
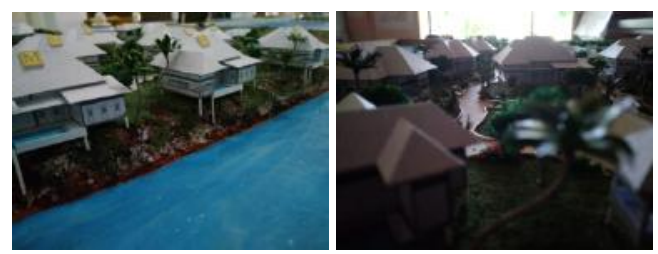

Gambar 29. Bangunan Resort

(Sumber : Dokumentasi pribadi)

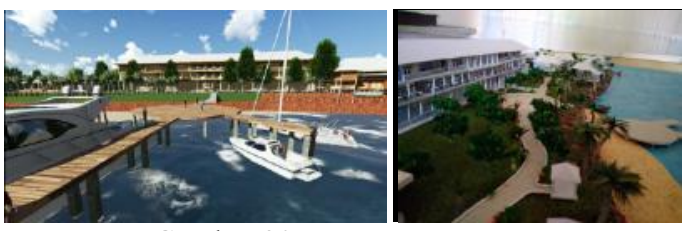

Gambar 30. Bangunan Utama

(Sumber : Dokumentasi pribadi)

\section{KESIMPULAN DAN SARAN}

Perencanaan Hotel Resort Pulau Jemur merupakan perencanaan aktivitas yang mewadahi para wisatawan yang berkepentingan dengan kegiatan berpariwisata, baik wisata bahari, wisata alam, wisata edukasi dan lainnya.

Pengembangan pulau jemur ini sebagai objek wisata dengan salah satunya memberikan akomodasi dan fasillitas lainnya. Selain itu untuk meningkatkan kepariwisataan pulau jemur sendiri memiliki potensi alam baik pasir putihnya, penangkaran penyu, sun rise dan sebagainya.

Adapun harapan dalam perencanaan Hotel Resort Pulau Jemur ini adalah dapat mewujudkan tempat Rekreasi dan pariwisata sehingga dapat menarik wisatawan baik dari lokal maupun internasional untuk dapat meningkatkan perekonomian yang ada di Rokan Hilir.

\section{DAFTAR PUSTAKA}

Asiyanto. 2012. Metode Konstruksi Untuk Pekerjaan Fondasi.

\section{Badan Perencanaan Pembangunan Daerah Kabupaten Rokan Hilir.}

Samra, B. (2015). Konsep Ruang Dalam Rumah Lama di Kawasan Senapelan Pekanbaru. Jurnal Arsitektur Melayu dan Lingkungan, 2(1). 
236 Jurnal Teknik, Volume 12, Nomor 2 Oktober 2018 ,pp 227 - 236

Samra, B., \& Imbardi, I. (2018). Penerapan Aspek Iklim Tropis pada Arsitektur Lokal Rumah Tradisional Melayu Studi Kasus di Desa Lalang Siak Sri Indrapura. JURNAL TEKNIK, 12(1), 68-76.

D.K. Ching,Francis. 2008.Arsitektur bentuk, ruang, dan tatanan.

Frick,Heinz. $\quad$ 1998.. Sistem Bnetuk Struktur Bangunan Dasar-dasar konstruksi dalam arsitektur.

Neufert, Ernest. 1936,Data Arsitek.

Masterplan Infrastruktur di Gugusan Kepulauan Aruah

Roberts et al (1984) Planning and Ecology.

Sudarmin S.T.,M.T Konsep Dasar Perancangan Arsitektur Melayu..

Jurnal Tinjauan Hotel Resort .

Jurnal Donni Enfido Simanjuntak Tinjauan Hotel Resort.

Jurnal Tinjauan Pustaka Universitas Sumatera Utara.

Jurnal bab ii tinjauan putaka universitas islam negeri maulana malik Ibrahim. 